\title{
Development of a Design System for the Seedbed Water-waving Irrigation Device
}

\author{
LIU Jiwei ${ }^{1, a}$, GUO $\mathrm{Yi}^{1, \mathrm{~b},{ }^{*}, \mathrm{CHEN} \text { Zhuo }}{ }^{2, \mathrm{c}}$ \\ ${ }^{1}$ Department of Horticulture, Beijing Vocational College of Agriculture, Beijing, 102442, China \\ ${ }^{2}$ Landscape Floriculture Specialty, Beijing Electrical Engineering School, Beijing, 100025, China \\ a1391900208@163.com, bguoyibvca@163.com, *corresponding author, '1054174790@qq.com
}

Keywords: Seedbed; Irrigation device; Design system; Development

\begin{abstract}
To avoid waste of water resources by existing irrigation devices, a seedbed water-saving irrigation device is designed, to substantively save irrigation water, realize automatic irrigation and save labor cost. Visual Basic and SolidWorks redevelopment technologies are used to develop a design system for the seedbed water-saving irrigation device. This system can automatically calculate design parameters based on users' parameters and then create a design drawing. Application examples show that design parameters calculated with this system are accurate and the design drawing produced can directly be used for device manufacturing, which can effectively shorten the design and manufacture period, raise efficiency and accordingly facilitate device promotion in the seedbed cultivation field.
\end{abstract}

\section{Introduction}

Protected agriculture is a distinctive sign of modern agriculture. Its promotion is an important task in agriculture modernization. Currently greenhouses are the main form of protected agriculture in China [1] [2]. Seedbed cultivation applied in the greenhouse can enhance space utilization ratio and improve people's operation convenience, so that it has become a commonly-found production mode. Vegetable cultivation in the form of pot culture on the seedbed can effectively avoid ground low temperature, decrease occurrence of plant diseases and insect pests and also facilitate manual operations. In today's practice, pot-cultured vegetables mainly adopt sprinkling irrigation, in which case, the spray head sprays mist to irrigate vegetables. Yet in the irrigation process, some pots shaded under leaves cannot be fully irrigated. Besides irrigation water falls in the gaps between pots, a waste of water, which is especially true for vegetables on edges of the seedbed. In addition, the radiation distance of spray heads sometimes cannot cover the vegetables; as a result, manual irrigation will be needed. Even if extra spray heads can be installed above those areas, the irrigation water may spray on ground outside the seedbed to cause water waste.

To raise design efficiency of mechanical products and shorten design period of the product, SolidWorks redevelopment technologies are used to realize 3D parameterized design model. Guo Yi developed a synchro-belt design system [3]; Li Zhi developed a parameterized design system for the plastic package structure [4]; Guo Yi developed a vertical cultivation design system [5]; Wang Jun, et al. performed parameterized modeling for the seedling cup maker [6]; Ge Huahui designed a wheeltread design system [7]; Guo Ying made parameterized deign of enclosure for the industrial flat bed sewing machine [8]; Sheng Jian made disc cam parameterized design [9]; and Li Weiliang made parameterized design of the hydraulic cylinder [10].

To solve the above problem, a seedbed water-saving irrigation device was designed, to ensure irrigation uniformity of pot-cultured vegetables in seedbed. It can avoid waste of irrigation water. Besides, it can irrigate automatically to save labor cost. To shorten the design and manufacturing period of the device, Visual Basic and SolidWorks redevelopment technologies are used to develop a design system for the seedbed water-saving irrigation device. This system can automatically calculate design parameters based on users' parameters and then create a design drawing. 


\section{Design of Overall Structure}

Composition of the Seedbed Water-saving Irrigation Device. The seedbed water-saving irrigation device is composed of the water tank, water pump, water inlet pipe, inlet valve, return pipe, return valve, water level control box, controller, pot support, and water pipe network. The water tank is designed to store irrigation water, with the upper part connecting water inlet pipes and water pipe network and the inside installed with a water pump. The water pump fetches water from the water tank and feed to the water level control box when needed. One end of the water inlet pipe is connected with the water pump and the other with the water level control box. In the middle of the water inlet pipe are furnished with inlet valves. When the inlet valve opens, water can be delivered to the water level control box from the water tank. One end of the return pipe is connected with the water tank and the other with the water pipe network. When the return valve opens, water can return to the water tank from the water pipe network. The pot support is round, each at the bottom having the water inlet pipe connected with the water pipe network. The water pipe network is a network of pipelines for transporting water. In the pipeline there are several joints connecting water inlet pipes of the pot support. At the bottom of the water level control box are two interfaces, one for connecting the water inlet pipe and the other for connecting the water pipe network. The water level sensor is installed in the water level control box, to control the water level, which is the same as the highest water level of the pot support. The controller is installed at the top of the water level control box and used for setting the irrigation starting and ending time.

Working Process of the Seedbed Water-saving Irrigation Device. When the irrigation starting time is reached, the controller controls opening of the inlet valve and the water pump, in which case, water is fed to the water level control box from the water tank. When the highest water level of the water level sensor is reached, the water level sensor sends signals to the controller, which will stop the water pump and shut down the inlet valve. At this time, water from the water pipe network has enabled water level in the pot support to be the same as that in the water level control box. Water is drawn to the cultivation pot under the capillarity of matrix in the cultivation pot through holes in the bottom of the pot. In this way, irrigation of the pot-cultured vegetables is realized. After a period of irrigation, when the irrigation ending time is reached, the controller controls opening of the return valve, when water from the pot support and water pipe network returns to the recovery tank. This is a round of irrigation work. When the next irrigation starting time is reached, the foregoing irrigation process will be repeated. From the structure and working process of this device it can be observed that this device can enable irrigation uniformity of pot-cultured vegetables, avoid water waste, realize automatic irrigation and reduce the labor cost.

\section{System Development}

System Function Analysis. The design system for the seedbed water-saving irrigation device shall be able to work out structural parameters of the irrigation device and create the design drawing according to users' requirements such as seed spacing and row spacing of the pot-cultured vegetable and specification of the cultivate bed.

System Development Flow. First, as per functional requirements of the system, Visual Basic is used to design the user interface; then, Visual Basic is used to write programs to work out design parameters according to users' parameters; finally, Visual Basic and SolidWorks redevelopment technologies are applied to update structural parameters of the preliminary model of the seedbed water-saving irrigation device according to the design parameters and then produce the design drawing.

Design of the User Interface. The user interface of this system mainly functions in inputting users' parameters and displaying design parameters. User parameters include the seed spacing of the pot culture, row spacing of the pot culture, seedbed length/width, and pot floor diameter. Design parameters include the cultivation number of rows, number of plants per row, number of pot support, diameter of the pot support, and total length of the water pipe. According to functional requirements the user interface designed with Visual Basic is shown in Fig.1. 
Calculation of the Design Parameters After analyzing users' parameters, the computing formula of the design parameters is as follows:

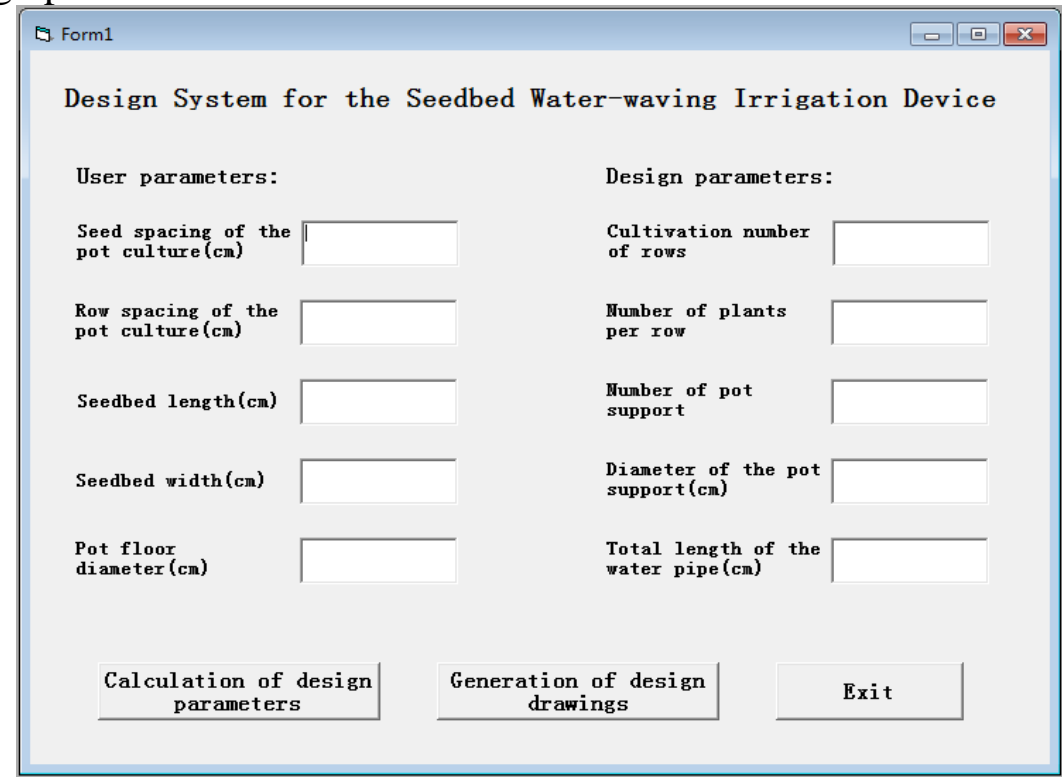

Fig. 1 User Interface

$$
\begin{aligned}
& h=\mathrm{w} / a \\
& z=l / b \\
& n=h \times z \\
& g=(l-b) \times h+(w-a) \times 2 \\
& D=d \times 20 \%
\end{aligned}
$$

Where, $w$ - seeded width $(\mathrm{cm}) ; l$ - seedbed length $(\mathrm{cm}) ; a$ - row spacing $(\mathrm{cm}) ; b$ - seed spacing $(\mathrm{cm}) ; h$ - cultivation number of rows; $z$ - number of plants per row; $n$ - total number of plants (number of pot support); $g$ - total length of water pipes (cm); $D$ - pot support diameter; $d$ - pot floor diameter.

With the foregoing formula, design parameters can be worked out based on parameters input by the user.

Generation of the Design Drawing. First, SolidWorks is used to draw preliminary models of parts and assemblies. Second, SolidWorks redevelopment interfaces are used to update the preliminary models according to design parameters to produce the design drawing.

\section{Application Examples}

Currently a $1500 \mathrm{~cm}$ long and $180 \mathrm{~cm}$ wide seedbed is used for pot culture vegetable production, requiring the seed spacing being $36 \mathrm{~cm}$, row spacing $36 \mathrm{~cm}$ and pot floor diameter $14 \mathrm{~cm}$. Design parameters from this design system are as follows: the cultivation number of rows is 5, number of plants per row 42 , number of pot support 210 , pot support diameter $17 \mathrm{~cm}$, and total length of water pipes $7608 \mathrm{~cm}$, as shown in Fig. 2. The design drawing produced is shown in Fig. 3. Application results of the device show that the design parameters are accurate and that the design drawing can directly be used for device manufacturing, which has effectively shortened the design and manufacturing period and raised efficiency.

\section{Conclusions}

A seedbed water-saving irrigation device is designed to avoid waste of water resources of existing irrigation devices, realize automatic irrigation and save labor cost. Visual Basic and SolidWorks redevelopment technologies are used to develop a design system for the seedbed water-saving irrigation device. This system can automatically calculate design parameters based on users' parameters and then create a design drawing. Application examples show that design parameters 
calculated with this system are accurate and the design drawing produced can directly be used for device manufacturing, which can effectively shorten the design and manufacture period, and raise efficiency.

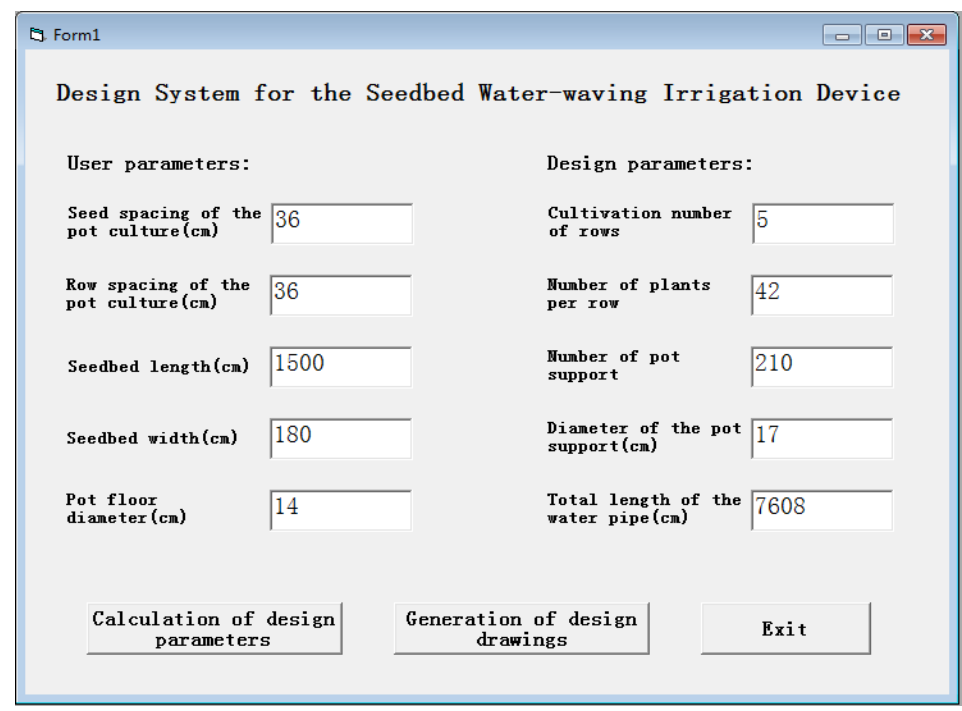

Fig. 2 Design Parameters

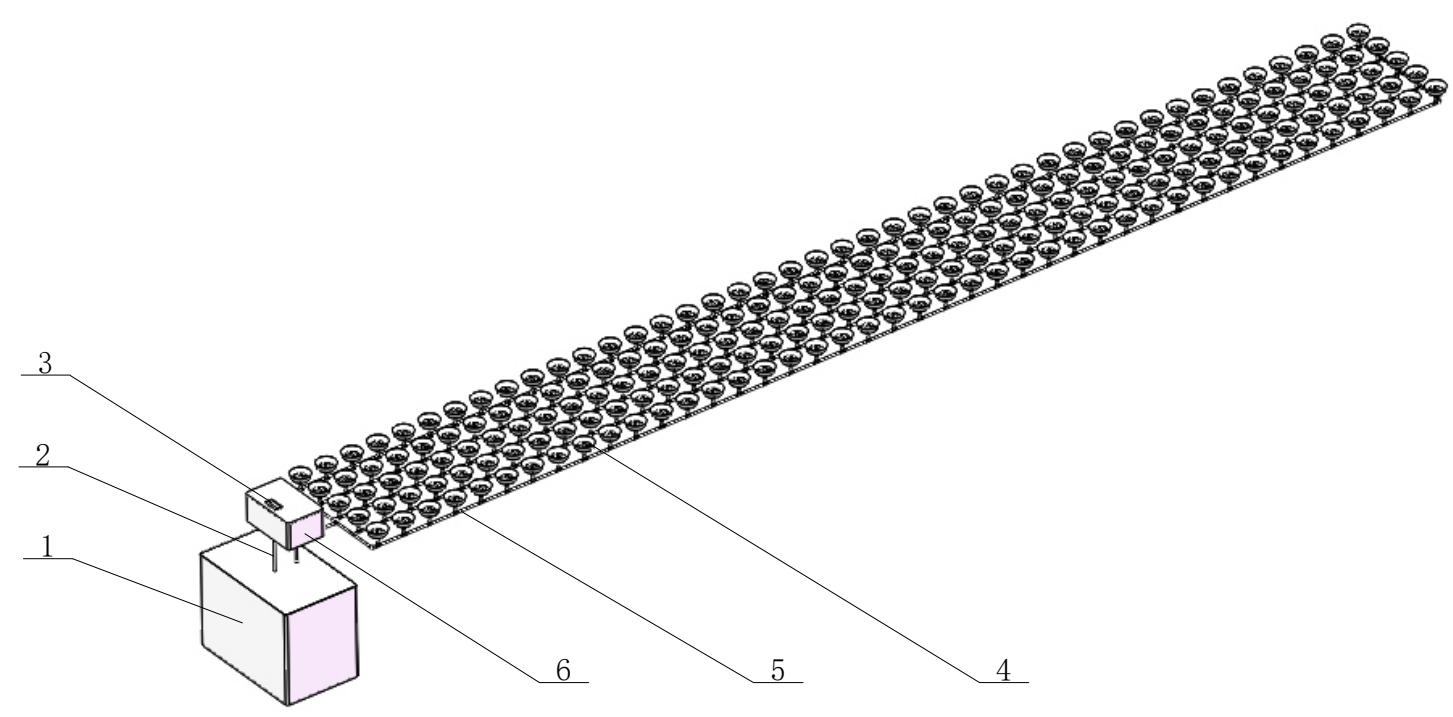

Fig. 3 Design drawing

1- water tank and water pump 2- water inlet pipe and return pipe 3- controller 4- pot support 5- water pipe network 6- water level control box

\section{Acknowledgement}

This article is funded by the Cultivation Technology Research and Demonstration on Special Leaf Vegetables like Ice Plants Project (Project No.: XY-YF-17-01) of Technology Development and Demonstration and Promotion Fund of Beijing Vocational College of Agriculture).

\section{References}

[1] SI Huiping, ZHOU Chen, WU Junhui, LIN Kaiyan, CHEN Jie. Research on the Development Status of Automatic Mobile Seedbed Control System [J]. Journal of Agricultural Mechanization Research, 2017, 39 (12): 258-263.

[2] GAO Yichuan, WU Zexing, WAN Yong, WANG Rui. Design for Mobile Seedbed Controller with Plastic Film Rolling Covering and Temperature Control [J]. Hubei Agricultural Sciences, 2016, 55(23): 6250-6253. 
[3] Yi GUO, Guoliang DING, Zhiqiang LI. Development and Application of a Synchronous Belt Drive Design System [J]. Advanced Materials Research, 2014, V971-973: 428-431.

[4] LI Zhi, AN Weisheng, WU Yuling, LI Yunzhe. Parameterized System for Encapsulation Machine Based on Solid Works [J]. Packaging Engineering, 2015, 36(15): 104-107+118.

[5] GUO Yi, ZHANG Guiqin. Development of A Design System for the Sprout Vertical Cultivation Device [J]. Advances in Engineering Research, 2015, Vol.26: 209-211.

[6] WANG Jun, LIU Minggang, TANG Jingyu. Structural Design of Nursery Cup Making Machine Based on Parametric Modeling [J]. Forestry Machinery \& Woodworking Equipment, 2015, 43(08): 14-18.

[7] GE Huahui, DING Yi, CHEN Jinfu, YING Lianhua, DONG Yude. Development of Tread Pattern Design System Based on Solid Works [J]. Tire Industry, 2016, 36(10): 587-591.

[8] GUO Ying, CAO Jujiang, ZHANG Keyu. Parametric Design Based on SolidWorks for Industrial Sewing Machine Casing [J]. Mechanical Engineering \& Automation, 2016, (03): 24-25.

[9] SHENG Jian, DAI Zuoqiang, ZHANG Hongxin. SUN Qi-na, WAN Mingle. Disc Cam Parameterized Design Based on SolidWorks [J]. Mechanical Engineering \& Automation, 2016, (02): 47-49.

[10]LI Weiliang, WANG Yixiang. Parametric Design of Hydraulic Cylinder with Secondary Development Based on Solidworks [J]. Machine Building \& Automation, 2017, 46(01): 74-77. 